\title{
Mornitoring and Identification of Human Astrovirus from Groundwater in Korea Based on Highly Sensitive RT-nested PCR Primer Sets
}

\author{
Siwon Lee ${ }^{1, *}$, Kyung Seon Bae ${ }^{2, * *}$, Jihyun Park ${ }^{2, * * *}$, Jin-Ho Kim ${ }^{3,4, * *}$, Jin-Young Lee ${ }^{1, * * *}$, \\ Jiwon Choi ${ }^{1,5 * * * *}$, Eung-Roh Park ${ }^{2, * * *}$ and Kyung-A You ${ }^{2, ;, * * *}$ \\ ${ }^{1}$ R\&D Team, LSLK Co. Ltd., Gimpo, Gyeonggi 10111, Korea \\ ${ }^{2}$ Water Supply and Sewerage Research Division, National Institute of Environmental Research, Incheon 22689, Korea \\ ${ }^{3}$ Institute of Tissue Regeneration Engineering (ITREN), Dankook University, Chunam 31116, Korea \\ ${ }^{4}$ Department of Chemistry, College of Science and Engineering, Dankook University, Chungnam 31116, Korea \\ ${ }^{5}$ Department of Chemical and Biochemical Engineering, Dongguk University, Seoul 04620, Korea
}

\begin{abstract}
Human Astrovirus (HuAstV) is an important gastrointestinal pathogen that is frequently reported worldwide. Monitoring of contaminated groundwater has been suggested since HuAstV is transmitted through the fecal-oral route. This study developed a test method based on conventional reverse transcription (RT)-nested polymerase chain reaction (PCR) that involves $\mathrm{SL}^{\circledR}$ non-specific reaction inhibitor for unknown non-specific amplification taking place in the groundwater environment. An optimal method for detecting $\mathrm{HuAstV}$ in groundwater sample through analysis and comparison against conventionally reported method was also suggested. The developed method enabled the production of nested PCR amplicon of $630 \mathrm{nt}$, which is a sufficient length for similarity analysis based on sequencing and genotyping. Amplicons suspected to be HuAstV were amplified in two out of the twenty groundwater samples collected in Korea, presenting 99.77\% and 99.73\% similarity against HuAstV 1 strain lhar/2011/kor (JN887820.1) in sequencing, respectively. These amplicons were identified as HuAstV 1.
\end{abstract}

Key Words: Human Astrovirus, HuAstV, Groundwater, $\mathrm{SL}^{\circledR}$ Non-specific reaction inhibitor

\section{서 론}

Human Astrovirus (HuAstV)는 Astroviridae, Mamoastrovirus 로 분류되며, 8개의 serotypes이 보고되었다(Krishna, 2005). 사람에게 감염될 경우 통상적 잠복기는 약 3 4일을 거쳐 질병 기간은 1 4일로, 식욕부진, 고열, 구토, 복통 등을 동반한 경증의 설사가 지속된다(Yi et al., 2004). 전 세계적 으로 5 세 미만 영아의 경우 약 17 억 건의 사례와 52.5 천 명의 사망자가 발생되었고, 9 세 이상의 약 $90 \%$ 가 $\mathrm{HuAstV}$ 에 대한 항체를 가지고 있어 사람의 장관계 질병 중 중
요한 병원체로 보고되고 있다(Johnson et al., 2017; Hargest et al., 2020). 국외에서는 2017년 3월 스페인의 어린이집에 서에서 증상이 나타난 임상 환자 중 6건과 무증상 감염 자 4건이 보고(Parrón et al., 2021), 2017년 11월 중국에서 12 17세 125명(Tan et al., 2019)의 발생이 보고되었으며, 국 내에서는 장염환자 중에서도 약 $1.0 \sim 1.9 \%$ 로 낮은 수준이 었으나, 최근 5년(2016 2020) 동안 2,521건의 임상 환자 보고로 연 평균 약 504 명의 $\mathrm{HuAstV}$ 감염이 보고되면서 주요 장관계 바이러스 중 약 $5.4 \%$ 정도를 차지하고 있다 [Korea Centers for Disease Control and Prevention (KCDC), 2021]. $\mathrm{HuAstV}$ 는 분변-구강 경로로 감염되므로 굴, 홍합

Received: September 16, 2021 / Revised: November 15, 2021 / Accepted: November 15, 2021

${ }^{*}$ Research director, ${ }^{* *}$ Researcher, ${ }^{* * *}$ Senior Researcher, ${ }^{* * *}$ Undergraduate student.

$\dagger$ Corresponding author: Kyung-A You. Water Supply and Sewerage Research Division, National Institute of Environmental Research, Incheon 22689, Korea. Tel: +82-32-560-8353, Fax :+82-32-563-7085, e-mail : angelka@korea.kr

(C) The Korean Society for Biomedical Laboratory Sciences. All rights reserved.

(C) This is an Open Access article distributed under the terms of the Creative Commons Attribution Non-Commercial License (http://creativecommons.org/licenses/by-nc/3.0/) which permits unrestricted non-commercial use, distribution, and reproduction in any medium, provided the original work is properly cited. 
등 패류로부터도 감염될 수 있으며, 2001 2012년 일본 오 사카에서 286건의 위장염 발병 사례 중 88 건(약 $30.7 \%$ ) 의 검체에서 검출 및 2014 2015년 이탈리아의 홍합 중 $16.0 ~ 32.0 \%$ 수준으로 검출된 바 있다(Iritani et al., 2014; Fusco et al., 2017). 또한 HuAstV는 수인성 장관계 바이러 스로 지하수와 지표수에서 약 15 일 동안 감염성이 감소 되지 않았고, 몇 달 동안 감염성이 유지된 것이 보고되면 서(Espinosa et al., 2008), 소규모 급수시설, 마을상수 등의 비 소독 또는 소독 관리에 취약한 급수 시설에서의 모니 터링 필요성이 제기되었으나, 현재 국내 지하수에서는 노 로바이러스, 총대장균군 및 대장균 항목만이 모니터링 되고 있다. 지하수 등 수계 환경에서 수인성 바이러스를 모니터링 하는 방법은 시료 채취, 탈리 및 농축 후 총 핵 산에서 중합효소연쇄반응(polymerase chain reaction; PCR) 기반으로 특이적 병원체의 핵산을 증폭하는 방법이 활용 되고 있고, 이 중에서도 높은 안정성, 넓은 범위의 사용 자 보유 및 염기서열 분석을 통해 genotyping이 가능한 일반 PCR 방법을 활용되고 있다(Lee and Cho, 2019). 국 내에서도 질병관리청, 식품의약품안전처 등 기관과 몇몇 문헌에서 $\mathrm{PCR}$ 기반의 검사법이 활용되고 있으나 $[\mathrm{KCDC}$, 2015; Korea Ministry of Food and Drug Safety (KMFDS), 2015; Lee and Rho, 2020], 지하수 등 수계 환경 시료로의 적용 연구는 미흡하며, 지하수 중 바이러스 핵산의 미량 오염 및 다수의 PCR 저해물이 포함될 가능성으로 인하 여 우수한 검출 민감도를 가진 nested PCR 수준 이상의 검출 민감도가 필요하다(Lee and Cho, 2019; Lee et al., 2021). 한편, 국내 임상 환자에 대한 연구에 비해 지하수에서의 $\mathrm{HuAstV}$ 모니터링에 대한 연구는 미흡하여 국내 지하수 중 $\mathrm{HuAstV}$ 의 현황, 검출되는 유전형, 발생되는 환자들과 의 관련 연구 등을 위해서는 지하수 중 $\mathrm{HuAstV}$ 모니터링 용 검사 시스템과 모니터링이 필요하다. 따라서 이번 연 구에서는 일반 역전사(reverse transcription)-nested PCR 기 반의 검사법을 개발 및 기존 보고된 RT- 또는 RT-nested PCR 방법과 함께 비교·분석하였으며, 몇몇 지하수 시료 에서의 활용성을 평가 및 검출된 $\mathrm{HuAstV}$ 의 유전형을 분 석하였다.

\section{재료 및 방법}

\section{HuAstV 특이적 프라이머 조합 및 바이러스 핵산 수집}

$\mathrm{HuAstV}$ 특이적 결합이 가능한 일반 RT-PCR, 실시간 RT-PCR, 등온증폭법 등의 정방향과 역방향 프라이머를 annealing 온도 $51 \sim 59^{\circ} \mathrm{C}\left(\right.$ 최적 $55^{\circ} \mathrm{C}$ )에서 반응할 수 있도록 변형 및 배합하여 20개 후보 RT-PCR 프라이머 조합을 구 성하였으며, 이 중 400 900 nucleotide (nt)의 증폭 산물 형 성이 기대되는 11 개를 후보 RT-PCR 프라이머 조합으로 하였다(Table 1) [Lee and Rho, 2020; KCDC, 2015; KMFDS, 2015; National Institute of Environmental Research (NIER), 2016, 2017]. 한편, 미국 국립생물공학정보센터(National Center for Biotechnology Information; NCBI) accession number JN887820를 기준으로 HuAstV ORF 1b-2 gene $(3,800$ 6,685 nt; 2,886 nt)의 핵산 단편을 (주)Marcrogen (Seoul, Korea)에서 합성하여 후보 RT-PCR 프라이머들이 모두 결합 및 반응할 수 있도록 하였다. 또한 비 특이적 반응 시험에 사용할 참고 바이러스 6종[Aichivirus A (AiV-A), Hepatitisvirus $A$ (HAV), Hepatitisvirus E (HEV), Norovirus GII (NoV-GII), Rotavirus-A (RV-A) 및 Sapovirus-GI (SaV-GI)] 을 핵산 단편을 함께 합성 또는 수집하였다(Lee and Cho, 2019; Lee et al., 2021).

\section{RT-nested PCR 프라이머 조합 선발 및 참고 프라이머 비교}

$\mathrm{HuAstV}$ 를 특이적으로 검출할 수 있을 것으로 추정되 는 11개 후보 RT-PCR 프라이머 조합을 대상으로 하여 i) $\mathrm{HuAstV}$ 핵산 단편에 특이적 반응 생성 여부, ii) HuAstV 핵산에 대한 검출 민감도 및 iii) 참고 바이러스 핵산 단 편의 비 특이적 반응 생성 여부를 확인하였다. i iii) 과정 을 통해 $\mathrm{HuAstV}$ 검출용 일반 RT-PCR 프라이머 조합을 선발하였으다. iv) 위의 ii) 과정의 RT-PCR 산물을 주형으 로 nested PCR 프라이머를 선발 및 검출 민감도를 분석 하였으며, v) 최종 선발한 nested PCR 프라이머 조합의 참고 바이러스 비 특이적 반응 생성 여부를 확인하였다. vi) 기존 보고된 RT-PCR 프라이머 조합들의 검출 민감도 및 참고 바이러스에 비 특이적 반응 생성 여부를 확인하 였다. 한편, RT-PCR 조성은 AccuPower ${ }^{\circledR}$ RT/PCR PreMix (Bioneer, Daejeon, Korea) dry type, 정방향 및 역방향 PCR 프라이머 각 $25 \mathrm{p}$ 로 $1 \mu \mathrm{L}$ (총 $2 \mu \mathrm{L}$ ), nucleic acid free water $17 \mu \mathrm{L}$, template $1 \mu \mathrm{L}$ 로 총 $20 \mu \mathrm{L}$ 로, 조건은 역전사 $\left(42^{\circ} \mathrm{C}\right.$, 60 분 $)$, 초기 변성 $\left(95^{\circ} \mathrm{C}, 10\right.$ 분 $), 35$ 회 반복 $\left(95^{\circ} \mathrm{C}\right.$ 에서 45 초, $55^{\circ} \mathrm{C}$ 에서 60 초, $72^{\circ} \mathrm{C}$ 에서 60 초), 최종 신장 $\left(72^{\circ} \mathrm{C}, 5\right.$ 분)으로 하였다(Lee and Cho, 2019; Lee et al., 2021). Nested PCR은 AccuPower ${ }^{\circledR}$ HotStart PCR PreMix (Bioneer) dry type을 사용 하여 RT-PCR과 동일한 조성 및 역전사 과정을 제외한 동일 조건으로 하였다(Lee and Cho, 2019; Lee et al., 2021). 
Table 1. Information of development combination and reference RT-nested PCR primer sets for the detection of human Astrovirus

\begin{tabular}{|c|c|c|c|c|c|c|c|c|c|}
\hline \multirow[b]{2}{*}{ Division } & \multirow{2}{*}{\multicolumn{2}{|c|}{ PCR type }} & \multicolumn{3}{|c|}{ Primer information } & \multicolumn{2}{|c|}{ Location $^{*}$} & \multirow{2}{*}{$\begin{array}{l}\text { Length } \\
\text { (nt) }\end{array}$} & \multirow[b]{2}{*}{ References } \\
\hline & & & Name & Sequence $\left(5^{\prime} \rightarrow 3^{\prime}\right)$ & $\begin{array}{l}\text { Mer } \\
\text { (nt) }\end{array}$ & Start & End & & \\
\hline \multirow{26}{*}{$\begin{array}{l}\text { Candidate } \\
\text { RT-nested } \\
\text { PCR } \\
\text { primer } \\
\text { sets in } \\
\text { this study }\end{array}$} & \multirow{2}{*}{$\begin{array}{l}\text { RT-PCR } \\
\text { primer set \#1 }\end{array}$} & \multirow{2}{*}{ RT-PCR } & HAstV_F30 & CTGACCTTGAATCACTCCAT & 20 & 4045 & 4064 & \multirow{2}{*}{848} & NIER, 2017 \\
\hline & & & Mon270R & TCAGATGCATTGTCATTGGT & 20 & 4873 & 4892 & & KMFDS, 2015 \\
\hline & \multirow{2}{*}{$\begin{array}{l}\text { RT-PCR } \\
\text { primer set \#2 }\end{array}$} & \multirow{2}{*}{ RT-PCR } & HAstV_F40 & GGAGCACTGCCTYTCRCG & 18 & 4133 & 4150 & \multirow{2}{*}{868} & NIER, 2017 \\
\hline & & & AstV_3_B3 & CACTCTGAAGCAAGTTCAA & 19 & 4982 & 5000 & & Lee and Rho, 2020 \\
\hline & \multirow{2}{*}{$\begin{array}{l}\text { RT-PCR } \\
\text { primer set \#3 }\end{array}$} & \multirow{2}{*}{ RT-PCR } & HAstV_F40 & GGAGCACTGCCTYTCRCG & 18 & 4133 & 4150 & \multirow{2}{*}{760} & NIER, 2017 \\
\hline & & & Mon270R & TCAGATGCATTGTCATTGGT & 20 & 4873 & 4892 & & KMFDS, 2015 \\
\hline & \multirow{2}{*}{$\begin{array}{l}\text { RT-PCR } \\
\text { primer set \#4 }\end{array}$} & \multirow{2}{*}{ RT-PCR } & AstV_1_F3 & AGGACCAAAGAAGTGTGAT & 19 & 4226 & 4244 & \multirow{2}{*}{775} & \multirow{2}{*}{ Lee and Rho, 2020} \\
\hline & & & AstV_3_B3 & CACTCTGAAGCAAGTTCAA & 19 & 4982 & 5000 & & \\
\hline & \multirow{2}{*}{$\begin{array}{l}\text { RT-PCR } \\
\text { primer set \#5 }\end{array}$} & \multirow{2}{*}{ RT-PCR } & AstV_1_F3 & AGGACCAAAGAAGTGTGAT & 19 & 4226 & 4244 & \multirow{2}{*}{841} & Lee and Rho, 2020 \\
\hline & & & HAstV_R40 & ACTTGMYTRTCTGTTGAYTT & 20 & 5047 & 5066 & & NIER, 2017 \\
\hline & \multirow{2}{*}{$\begin{array}{l}\text { RT-PCR } \\
\text { primer set \#6 }\end{array}$} & \multirow{2}{*}{ RT-PCR } & HAstV_F50 & AAGTGTGATGGCTAGCAAGT & 20 & 4236 & 4255 & \multirow{2}{*}{765} & NIER, 2017 \\
\hline & & & AstV_3_B3 & CACTCTGAAGCAAGTTCAA & 19 & 4982 & 5000 & & Lee and Rho, 2020 \\
\hline & RT-PCR & PT-PCP & HAstV_F50 & AAGTGTGATGGCTAGCAAGT & 20 & 4236 & 4255 & & 17 \\
\hline & & & HAstV_R40 & ACTTGMYTRTCTGTTGAYTT & 20 & 5047 & 5066 & 001 & 17we, 2017 \\
\hline & RT-PCR & PT DA $>>$ & $\mathrm{F} 3 \mathrm{~m}$ & GCARGTHACTGTTGAGGTC & 19 & 4263 & 4281 & 738 & This study \\
\hline & primer set \#8 & Nater & AstV_3_B3 & CACTCTGAAGCAAGTTCAA & 19 & 4982 & 5000 & 150 & Lee and Rho, 2020 \\
\hline & RT-PCR & DT Do $>$ & $\mathrm{F} 3 \mathrm{~m}$ & GCARGTHACTGTTGAGGTC & 19 & 4263 & 4281 & 801 & This study \\
\hline & primer set \#9 & Fer & HAstV_R40 & ACTTGMYTRTCTGTTGAYTT & 20 & 5047 & 5066 & 00 & NIER, 2017 \\
\hline & RT-PCR & $\mathrm{PT}$ & $\mathrm{F} 3 \mathrm{~m}$ & GCARGTHACTGTTGAGGTC & 19 & 4263 & 4281 & 886 & This study \\
\hline & primer set \#10 & 101 & HAstV_R30 & AAGTGCTGTCCGAGCAAART & 20 & 5129 & 5148 & 000 & NIER, 2017 \\
\hline & RT-PCR & DT DCD & $\mathrm{F} 3 \mathrm{~m}$ & GCARGTHACTGTTGAGGTC & 19 & 4263 & 4281 & 630 & This study \\
\hline & primer set \#11 & Fer & Mon270R & TCAGATGCATTGTCATTGGT & 20 & 4873 & 4892 & 050 & KMFDS, 2015 \\
\hline & Nested PCR & Nested & $\mathrm{F} 3 \mathrm{~m}$ & GCARGTHACTGTTGAGGTC & 19 & 4263 & 4281 & 738 & This study \\
\hline & primer set \#4-1 & PCR & AstV_3_B3 & CACTCTGAAGCAAGTTCAA & 19 & 4982 & 5000 & 150 & Lee and Rho, 2020 \\
\hline & Nested PCR & Nested & $\mathrm{F} 3 \mathrm{~m}$ & GCARGTHACTGTTGAGGTC & 19 & 4263 & 4281 & & This study \\
\hline & and \#8-1 & PCR & Mon270R & TCAGATGCATTGTCATTGGT & 20 & 4873 & 4892 & & KMFDS, 2015 \\
\hline & & PT D $C$ & HuAstV-2-B3 & ACAACTCAGGAAACAAGGT & 19 & 4443 & 4461 & 550 & \\
\hline & Ref. & אतs & HuAstV-3-B3 & CACTCTGAAGCAAGTTCAA & 19 & 4982 & 5000 & 500 & \\
\hline Reference & set A & Nested & HuAstV-3-F3 & GTAAGCACCTTGATGTTACA & 20 & 4778 & 4797 & 2 & 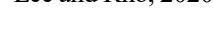 \\
\hline RT-nested & & PCR & HuAstV-3-B3 & CACTCTGAAGCAAGTTCAA & 19 & 4982 & 5000 & 225 & \\
\hline PCR & Ref. & RT-I & HuAstV-3-F3 & GTAAGCACCTTGATGTTACA & 20 & 4778 & 4797 & 223 & Lee and Rho 2020 \\
\hline sets & set B & 101 & HuAstV-3-B3 & CACTCTGAAGCAAGTTCAA & 19 & 4982 & 5000 & 225 & 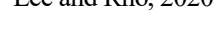 \\
\hline & Ref. & & Mon 269 & CAACTCAGGAAACAGGGTGT & 20 & 4444 & 4463 & 110 & KME \\
\hline & set C & N1-1 & Mon 270 & TCAGATGCATTGTCATTGGT & 20 & 4873 & 4892 & (T) & 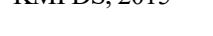 \\
\hline
\end{tabular}

*Based on NCBI accession number JN887820

한편, 비교 프라이머 조합 정보는 Table 1과 같으며, 기 존 보고된 조건 및 조성과 동일하게 하였다(Lee and Rho, 2020; KCDC, 2015; KMFDS, 2015; NIER, 2016, 2017).

\section{지하수 시료에서의 적용성 검토 및 모니터링}

국립환경과학원 고시 제 2017-50에 따라 전국 소규모급 수시설과 마을상수도를 대상으로 시료 20개를 채취하였 
다(자료 미 제공). 실험실로 이동하여 탈리 및 농축 후 RNeasy Mini Kit (Qiagen, Germany)를 사용하여 농축액에 서 total RNA를 추출하였다. 이번 연구에서 최종 선발한 RT-PCR 및 nested PCR 프라이머 조합, 비교 프라이머 조 합들 중 가장 우수한 검출 민감도가 나타난 1개(조합A) 및 기관에서 제공하는 프라이머 1 개(조합C)으로 총 3 개 조합들로 지하수 중 $\mathrm{HuAstV}$ 모니터링 및 적용성을 검토 하였다. 선발 프라이머를 사용한 RT-PCR은 AccuPower ${ }^{\circledR}$ RT/PCR PreMix (Bioneer), nested PCR은 AccuPower ${ }^{\circledR}$ HotStart PCR PreMix (Bioneer)를 사용하였으나, 지하수 등 환경 시료에서 나타나는 비 특이적 반응억제를 위해 RT- 및 nested PCR 모두 조성물로 $\mathrm{SL}^{\circledR}$ Non-specific reaction inhibitor (LSLK, Gyeonggi, Korea) $3 \mu \mathrm{L}$ 를 포함하여 총 $20 \mu \mathrm{L}$ 로 반 응하였다(Lee and Cho, 2019). 한편, 비교 프라이머 조합은 기존 보고된 조건 및 조성과 동일하게 하였고(Lee and Rho, 2020; KCDC, 2015; KMFDS, 2015; NIER, 2016, 2017), 산물들은 모두 $1.2 \%$ agarose gel에서 전기영동하였으며, 두 개의 방법으로 지하수에서 모니터링된 결과를 비교하였 다. 한편, 시료 중 추정 양성 염기서열이 나타난 밴드를 MEGAquick-spin ${ }^{\mathrm{TM}}$ Plus Total Fragment DNA Purification Kit (iNtRON, Gyeonggi, Korea)로 정제 후 (주)Marcrogen에서 sequencing하였다. 염기서열을 NCBI BLAST로 유사성을 분석하였다. 한편, 유전형 분석을 위하여 $\mathrm{HuAstV}$ genotype 1-8에 포함되는 32개 taxa 및 아웃 그룹으로 수인성 장관 계 바이러스 4종[HAV (NC_001489.1), HEV (NC_001434.1), human Enterovirus A (NC_001612.1) 및 AiV-A (NC_001918.1)] 을 수집 후, BioEdit ver. 7.1.3로 다중 염기서열 정렬하였 으며, MEGA software ver. 6.03을 사용하여 Neighbor-joining phylogenetic tree를 구축하였다(Hall, 1999; Tamura et al., 2013).

\section{결과 및 고찰}

\section{HuAstV RT-nested PCR 프라이머 조합 선발 및 참고 프 라이머 조합과의 비교}

$\mathrm{HuAstV}$ 특이적 증폭이 추정되는 11 개 후보 RT-PCR 프 라이머 조합들 중 3 개 조합(\#04, \#08 및 \#11)에서 775, 738 및 $630 \mathrm{nt}$ 로 기대되는 크기의 amplicon이 형성되었다(Fig. 1). 반응이 우수하고 산물의 크기가 상대적으로 큰 \#04와 $\# 08$ 을 선발하여 검출 민감도 및 비 특이적 반응 여부를 분석한 결과 조합 \#04는 $10 \mathrm{fg} / \mu \mathrm{L}$, 조합 \#08은 $1 \mathrm{fg} / \mu \mathrm{L}$ 나 타났으며, 두 개 조합 모두 참고 바이러스 핵산 6종에 대

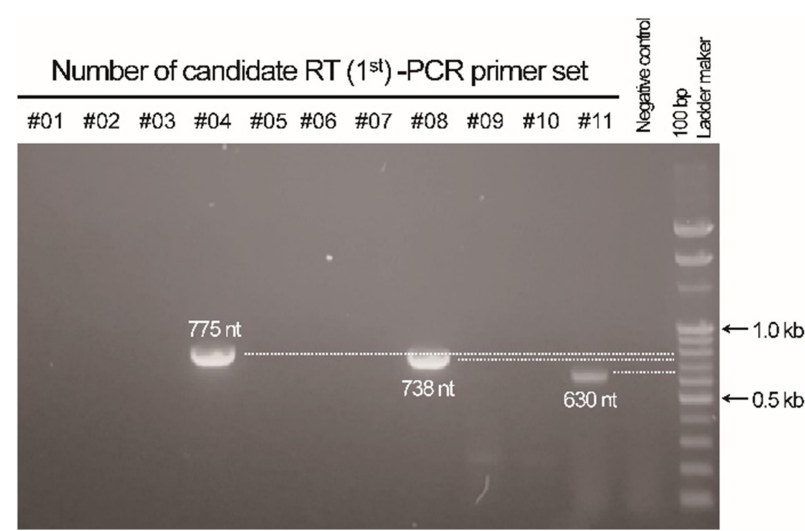

Fig. 1. Specific reaction of candidate RT-PCR primer sets for the detection of human Astrovirus (HuAstV). \#01-\#11, combination of candidate RT-PCR primer sets. A, candidate RT-PCR primer sets. B, candidate nested PCR primer sets. M, 100 bp Ladder marker (Enzynomics, Korea); $-3 \sim-8$, template dilution value from $1 \mathrm{ng} / \mu \mathrm{L}$ HuSaV plasmid; N, negative control, PN, PCR negative control.

\section{A}

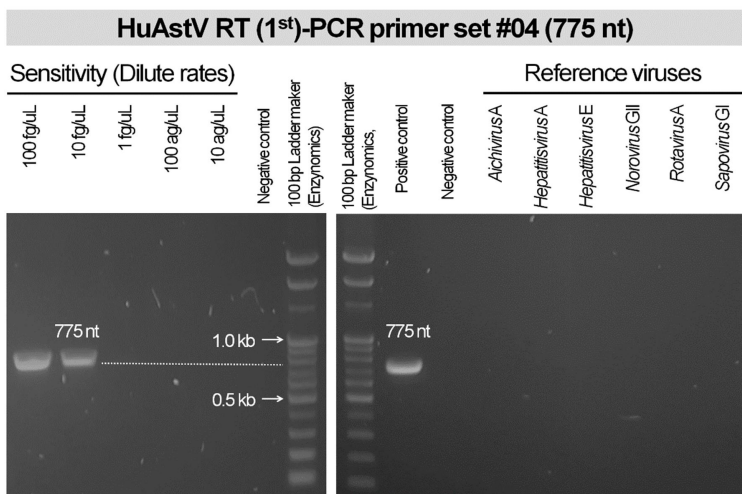

B

HuAstV RT (1 ${ }^{\text {st }}$-PCR primer set \#08 (738 nt)

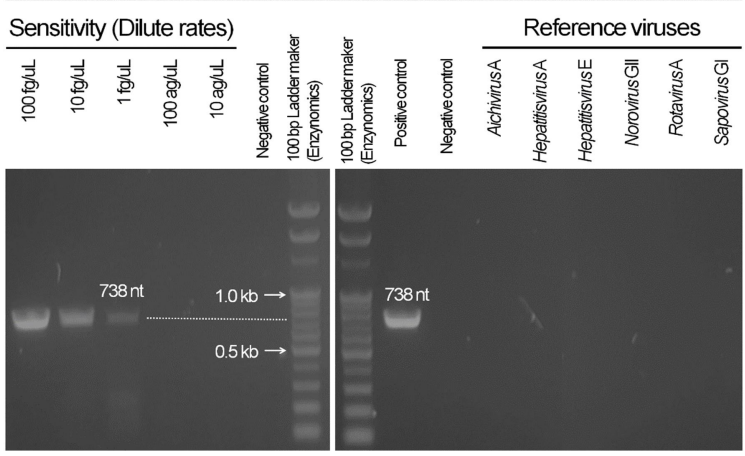

Fig. 2. Sensitivity and non-specific reaction tests of two candidate RT-PCR primer sets. (A) RT-PCR primer set \#04 (Amplicon size $775 \mathrm{nt}$ ). (B) RT-PCR primer set \#08 (738 nt). 
(A)

HuAstV nested (2n) PCR from RTPCR primer set \$04

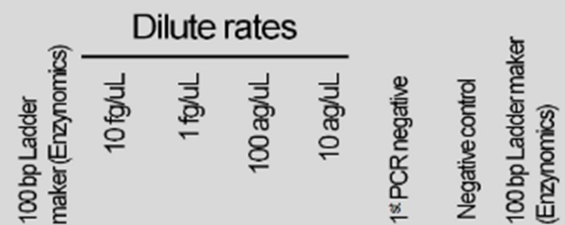

\section{Set\#04-1}

(738 nt)

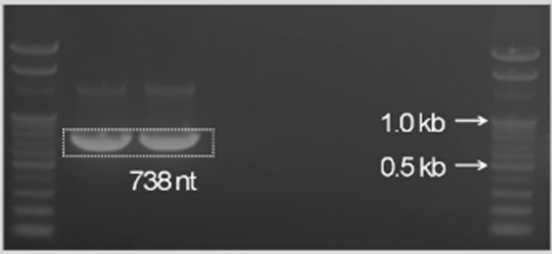

Set\#04-2

(630 nt)

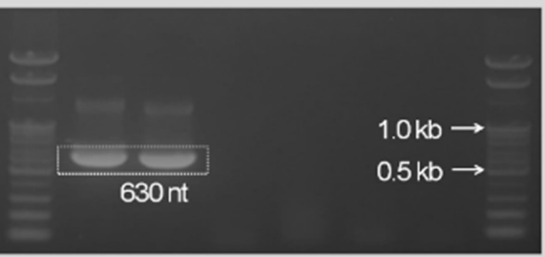

B

HuAstV nested (2nd) PCR primer set \#04-2 (630 nt)

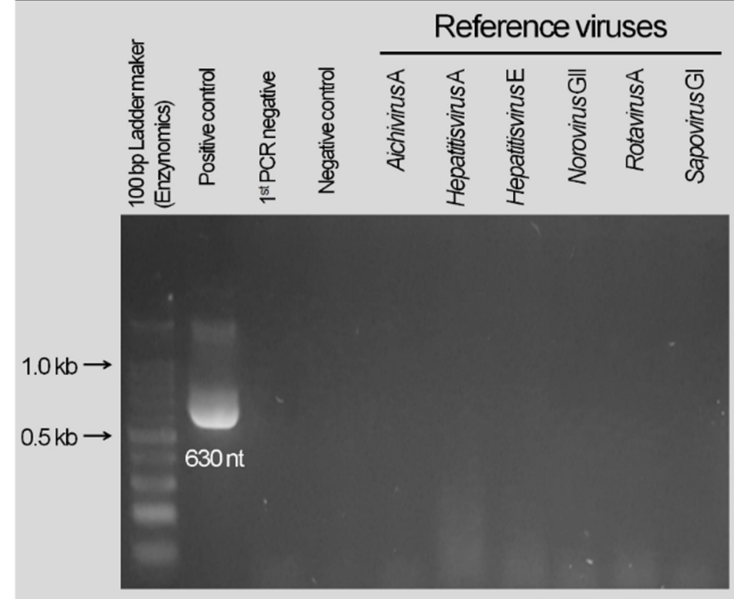

HuAstV nested (2nd) PCR from RTPCR primer set\#08

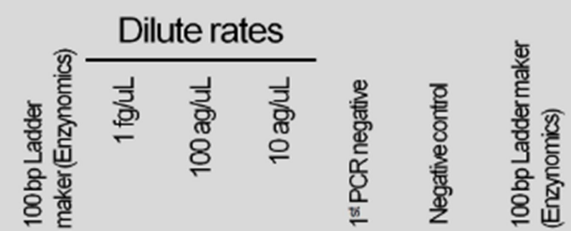

Set\#08-1

(630 nt)

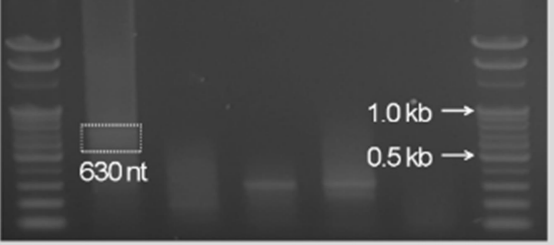

Fig. 3. Sensitivity and non-specific reaction tests of candidate nested PCR primer sets. (A) Two candidate nested PCR primer sets from RT-PCR \#04 and \#08. (B) non-specific reaction of selectived nested PCR primer set \#04-2 (630 nt).
한 비 특이적 반응은 없음에 따라 지하수에서 수인성 장 관계 바이러스를 검출할 수 있는 적합한 검출 민감도 수 준을 가진 RT-PCR 프라이머 조합으로 추정되었다(Fig. 2) (Lee and Cho, 2019; Lee et al., 2021). RT-PCR 조합 \#04 (775 nt) 로 부터는 2개[RT-PCR 프라이머 조합 \#08(= nested PCR 프라이머 조합 \#04-1) 및 \#11(= nested PCR 프라이머 조 합 \#04-2)], 조합 \#08 (738 nt)로 부터는 1개[RT-PCR 프라 이머 조합 \#11(= nested PCR 프라이머 조합 \#08-1)]의 후 보 nested PCR 프라이머 조합의 검출 민감도를 분석하였 다. 세 개의 후보 nested PCR 조합 모두 $\mathrm{HuAstV}$ 를 $1 \mathrm{fg} / \mu \mathrm{L}$
수준까지 검출할 수 있었으나 조합 \#08-1에서는 반응이 약했고 비 특이적 밴드가 함께 나타났으며, 조합 \#04-1 과 \#04-2에서는 동일한 결과가 나타남에 따라 RT-PCR 프 라이머 산물 크기인 $775 \mathrm{nt}$ 와 구분이 되는 \#04-2 (630 nt)를 선발하였다(Fig. 3A). 선발한 nested PCR 프라이머 조합의 참고 바이러스 6종에 대한 비 특이적 반응이 나타나지 않 음에 따라 최종 프라이머 조합으로 선발하였다(Fig. 3B). 한편, 3 쌍의 비교 프라이머 조합들 중, 조합 A와 B는 RTPCR에서는 $100 \mathrm{fg} / \mu \mathrm{L}$, nested PCR에서 $10 \mathrm{fg} / \mu \mathrm{L}$ 수준, 비교 프라이머 조합 C에서는 RT-PCR에서 $10 \mathrm{fg} / \mu \mathrm{L}$ 로 나타났으 

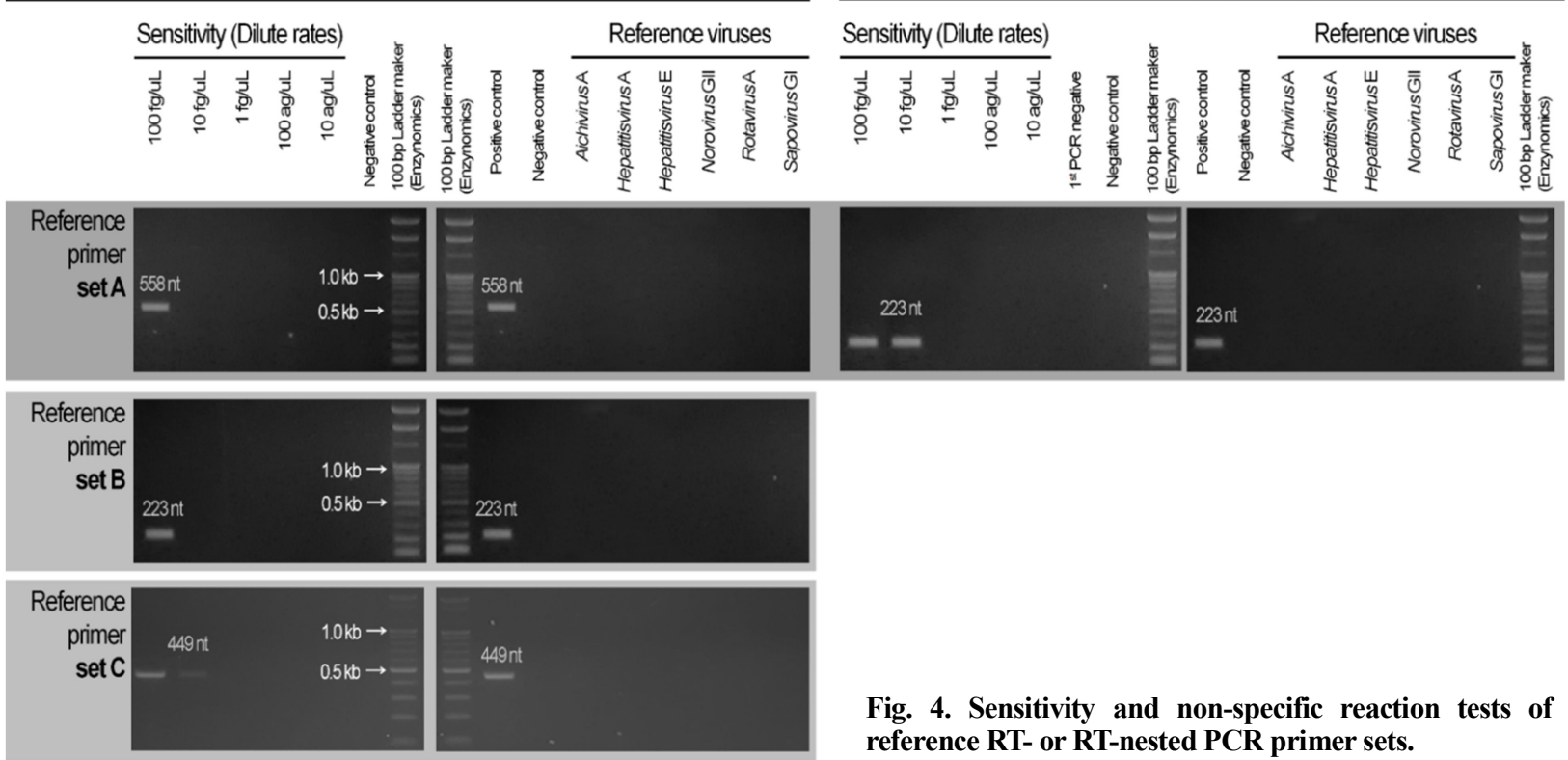

Fig. 4. Sensitivity and non-specific reaction tests of reference RT- or RT-nested PCR primer sets.

며, 참고 바이러스 6종의 핵산에 대한 비 특이적 반응은 모두 나타나지 않았다(Fig. 4). 이번 연구에서 선발한 RTnested PCR 프라이머 조합을 포함한 조성물 및 조건을 활 용할 경우, 비교 프라이머 조합 $\mathrm{A}$ 와 $\mathrm{B}$ 에 비해 동등 시간 대비 RT- 및 nested PCR에서 약 10 배 수준의 검출 민감도 향상될 수 있고, 비교 프라이머 조합 C와는 RT-PCR 수 준에서는 동등한 검출 민감도이지만 증폭 산물의 크기가 상대적으로 크다. 또한 선발 nested PCR 활용 시 약 2시간 의 반응 시간이 추가되지만 10 배 높은 검출 민감도 향상 이 기대된다.

\section{지하수 시료에서의 적용성 검토 및 모니터링}

전국 소규모급수시설과 마을상수도의 지하수 20 개에 서 추출한 total RNA로부터 선발한 RT-nested PCR 조합 으로 반응하였을 때 시료 \#1과 \#2에서 $630 \mathrm{nt}$ 의 추정 양 성 밴드가 나타났으나, 반면 비교 프라이머 조합 $\mathrm{A}$ 에서 는 시료 2에서, 비교 프라이머 조합 $\mathrm{C}$ 에서는 대부분의 시료에서 비 특이적 밴드와 끌림이 나타났다(Fig. 5). 이것 은 지하수 등 환경 시료 내 알 수 없는 PCR inhobotors 로 인해 순수한 핵산만 존재하는 상태에 비해 약 100 배 수준까지 검출 민감도가 저해될 수도 있으며, 알 수 없 는 비 특이적 반응이 다수 나타나는 것으로 설명될 수 있다(Lee and Cho, 2019; Lee et al., 2021). 선발 프라이머 조 합은 비교 프라이머 조합들에서 검출하지 못한 2 개 시

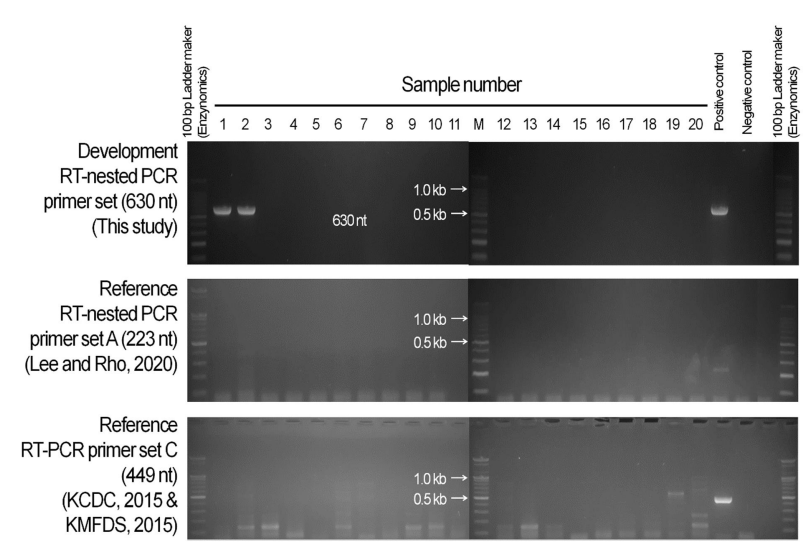

Fig. 5. Sample tests of developed RT-nested PCR primer set and two reference RT- or RT-nested PCR primer sets. 1 20, groundwater sample number.

료 내 $\mathrm{HuAstV}$ 특이적 핵산을 검출할 수 있었고, 증폭된 산물의 염기서열의 $\mathrm{NCBI} \mathrm{BLAST}$ 한 결과 시료 \#1과 \#2는 HuAstV 1 strain lhar/2011/kor (JN887820.1)와 각각 99.77\% 와 $99.73 \%$ 의 유사성이 나타났으며, 두 시료 간 염기서 열의 유사성은 $99.64 \%$ 였다. Genotyping 결과 모두 AstV genotype 1로 나타났으며, HuAstV strain lhar/2011/kor (JN887820.1), HuAstV type strain Dresden (AY720892.1) 및 $\mathrm{HuAstV}$ isolate JZ (KF211475.1)과 유연관계가 높았다(Fig 6). 한편, 비교 프라이머 조합 $\mathrm{A}$ 와 $\mathrm{C}$ 에서 증폭된 비 특이 


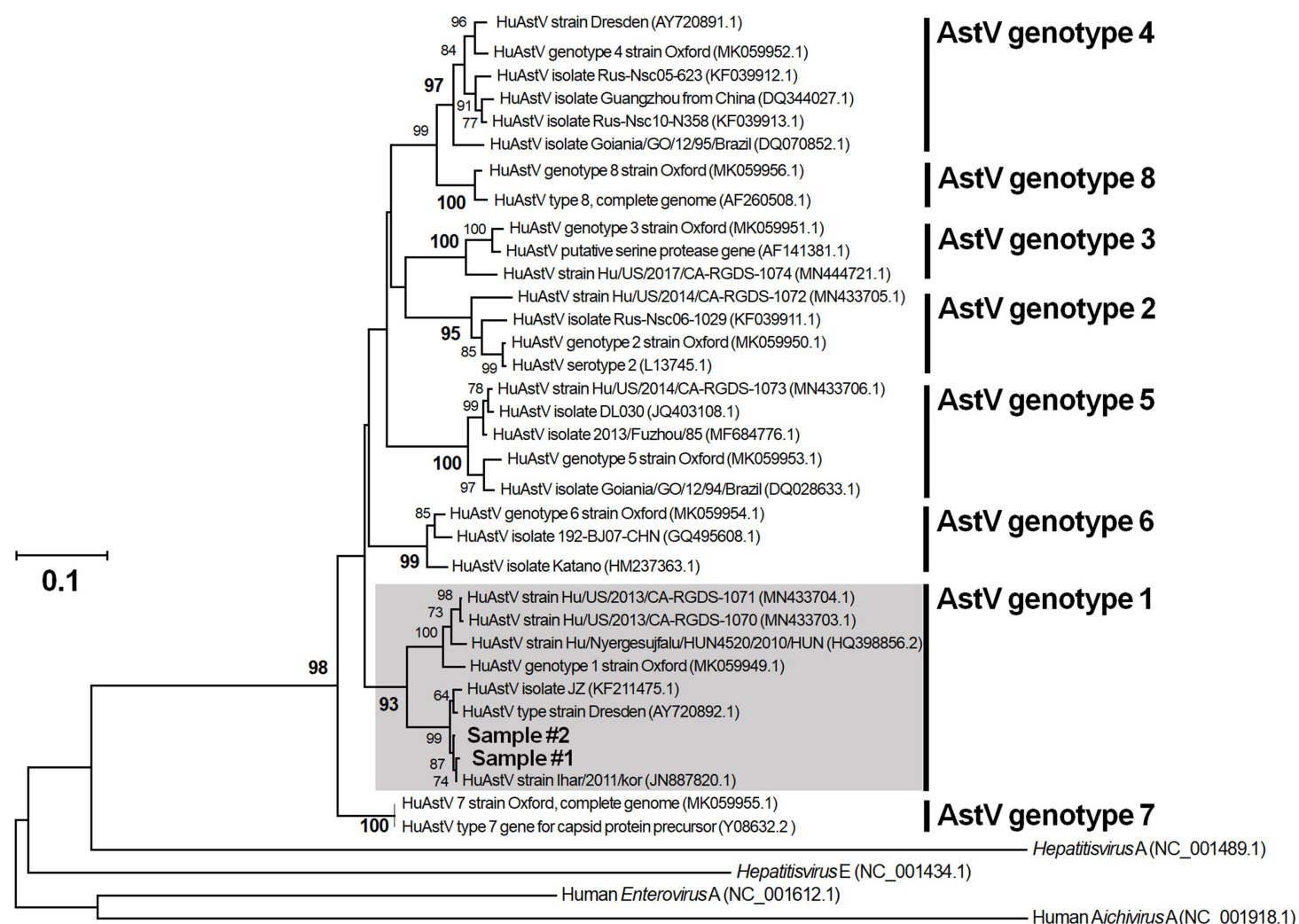

Fig. 6. Neighbor-joining tree showing the phylogenetic position of two HuAstV positive samples based on amplicon sequence using selectived nested PCR primer set (F3m and Mon270R). Bootstrap values $(<50 \%)$ based on 1,000 replications are shown. Waterborn enteric viruses [Hepatitisvirus A (NC_001489.1), Hepatitisvirus E (NC_001434.1), human Enterovirus A (NC_001612.1) and human Aichivirus A(NC_001918.1)] were used as out groups. Bar, 0.1 nucleotide substitutions.

적 밴드 중 증폭 크기와 유사한 밴드를 gel-purification 후 염기서열 분석을 수행하였으나 noise signal 등으로 모두 비 특이적 증폭으로 확인되었다. 이에 따라 이번 연구에 서 선발한 RT-nested PCR 프라이머 조합은 기존 보고된 비교 프라이머들에 비해 지하수에서의 활용성이 상대적 으로 용이하여 HuAstV 모니터링용으로 적합 할 것으로 보이며, 검출 민감도가 우수한 프라이머들의 조합과 함 께 비 특이적 억제 물질을 포함한 조성물의 이유로 추정 된다.

\section{지하수에서 HuAstV 모니터링법으로 활용}

이번 연구에서는 기본 보고된 conventional PCR 기반의 방법 대비 지하수 시료에서 고감도로 비 특이적 반응 없이 HuAstV의 핵산을 모니터링 할 수 있는 RT-PCR 및 nested PCR 프라이머 조합을 선발하였으며, 이를 활용하 여 지하수 중 $\mathrm{HuAstV}$ 를 모니터링 하는 방법은 다음과 같다; i) 국립환경과학원 고시 제 2017-50에 따라 지하수
시료를 채취 후 아이스 박스에 담아 실험실로 이동하여, ii) 탈리 및 농축을 시행한다. iii) 농축액 $140 \mu \mathrm{L}$ 로부터 RNeasy Mini Kit (Qiagen) 또는 동등 성능의 kit를 사용하 여 total RNA를 추출 및 nanodrop 등으로 회수된 핵산의 농도를 측정한다. iv) 프라이머 조합AstV_1_F3 (5'-AGG ACC AAA GAA GTG TGA T-3') 및 AstV_3_B3 (5'-CAC TCT GAA GCA AGT TCA A-3') (775 nt)을 사용하여 RT$\mathrm{PCR}$ 을 수행 후 $1.2 \%$ agarose gel에 러닝 및 gel documentation system에서 확인한다. 이때 HuAstV 핵산을 양성대조 군의 주형으로, 음성대조군으로는 nucleic acid free water 를 사용한다. v) 프라이머 조합 F3m (5'-GCA RGT HAC TGT TGA GGT C-3') 및 MON 270R (5'-TCA GAT GCA TTG TCA TTG GT-3') (630 nt)를 사용하여 nested PCR을 수행 후 $1.2 \%$ agarose gel에 러닝 및 gel documentation system에서 확인한다. 이때 양성대조군으로는 RT-PCR 양 성대조군의 증폭산물, RT-PCR negative의 증폭여부 검정 을 위해 RT-PCR 음성대조군의 증폭산물, nested PCR 음 
성대조군으로 nucleic acid free water를 사용한다. vi) Nested $\mathrm{PCR}$ 결과 약 $630 \mathrm{nt}$ 의 밴드가 형성되면 '추정 양성'으로 판정하고 염기서열 분석을 수행한다. 염기서열 분석 시 비 특이적 밴드가 나타나면 약 $630 \mathrm{nt}$ 의 밴드만을 gelpurification하여 sequencing하며, 신뢰 가능한 염기서열 부 분을 취하여 NCBI BLAST를 통해 query sequence의 similarity를 확인한다. vii) BioEdit, MEGA 등 software packages 를 통해 maximum likelihood 또는 neighbor joining 기반의 tree making method로 genotyping을 수행하여 최종 $\mathrm{HuAstV}$ 양성으로 확정할 수 있다.

한편, 환경부 국립환경과학원에서 소규모 수도시설, 마 을상수도 등의 음용 및 비음용 지하수 시료에서 노로바 이러스 만을 기준항목으로 모니터링을 시행하고 있다. 그 러나 수인성 장관계 바이러스는 약 150 여 종이 존재하며, 사람 외에도 수계, 식품, 패류 등 다양한 매질로부터 감 염이 이루어질 수 있어 중요한 병원체로 분류 및 보고되 면서(KCDC, 2015; KMFDS, 2015; NIER, 2016, 2017), 질병관 리청과 식약처를 중심으로 시도 보건환경연구원의 유관 시료에 미규제 수인성 장관계 바이러스 중 주요한 $\mathrm{HAV}$, $\mathrm{HEV}, \mathrm{SaV}, \mathrm{RV}-\mathrm{A}$ enteric Adenovirus 와 함께 HuAstV 등의 모니터링을 권고하고 있으며, 환경부 국립환경과학원에서 도 지하수에서 $\mathrm{HuAstV}$ 등 미 규제 수인성 바이러스에 대 한 연구를 수행하고 있다. 그러나 지하수 시료는 채취, 탈리 및 농축 등 전 처리에 많은 시간, 비용 및 노동력이 필요하며(Lee and Cho, 2019; Lee et al., 2021), 이번 연구에 서도 20 개 수준의 지하수 시료에서 모니터링을 수행하 였다. 이번 연구에서 개발한 방법의 검증, 국내 지하수 등 수계에 잠재적으로 존재하는 $\mathrm{HuAstV}$ 의 발생원 관리, 사전대응을 위한 근거자료의 구축 등을 위해서는 더욱 다 양한 지하수 시료로부터 모니터링이 필요할 것으로 보 인다.

\section{ACKNOWLEDGEMENT}

This work was supported by a grant from the National Institute of Environmental Research (NIER), funded by the Ministry of Environment (MOE) of the Republic of Korea (NIER-2020-01-01-003).

\section{CONFLICT OF INTEREST}

The authors declare that they have no conflict of interest.

\section{REFERENCES}

Espinosa AC, Mazari-Hiriart M, Espinosa R, Maruri-Avidal L, Méndez E, Arias CF. Infectivity and genome persistence of rotavirus and astrovirus in groundwater and surface water. Water Res. 2008. 42: 2618-2628.

Fusco G, Di Bartolo I, Cioffi B, et al. Prevalence of foodborne viruses in mussels in Southern Italy. Food Environ Virol. 2017. 9: $187-194$

Hall T. BioEdit: A user-friendly biological sequence alignment editor and analysis program for windows 95/98/NT. Nucleic Acids Symp Ser. 1999. 41: 95-98.

Hargest V, Sharp B, Livingston B, et al. Astrovirus replication is inhibited by nitazoxanide in vitro and in vivo. J Virol. 2020 94: e01706-19.

Iritani N, Kaida A, Abe N, et al. Detection and genetic characterization of human enteric viruses in oyster-associated gastroenteritis outbreaks between 2001 and 2012 in Osaka City, Japan. J Med Virol. 2014. 86: 2019-2025.

Johnson C, Hargest V, Cortez V, Meliopoulos VA, Schultz-Cherry S. Astrovirus pathogenesis. Viruses. 2017. 9: 22

Korea Centers for Disease Control and Prevention (KCDC). Practical guidelines for laboratory diagnosis of waterborne foodborne diseases. 2015. pp. 88-89. KCDC, Chungcheongbukdo, Korea.

Korea Centers for Disease Control and Prevention (KCDC). Infectious disease potal. 2021. http://www.kdca.go.kr/npt/biz /npp/iss/gastrointestinalStatisticsMain.do [accessed 12 August 2021].

Korea Ministry of Food and Drug Safety (KMFDS). Test method of food poisoning cause investigation. 2015. pp. 223-227. Chungcheongbuk-do, Korea

Krishna NK. Identification of structural domains involved in astrovirus capsid biology. Viral Immunol. 2005. 18: 17-26.

Lee JY, Rho JY. Development of diagnostic method for human astrovirus with rapid, specific and high sensitivity using loopmediated isothermal amplification method. Korean J Agric Sci. 2020. 47: 173-182.

Lee S, Cho KB. Development of reverse transcription semi-nested PCR primer pairs for the specific and highly sensitive detection of human aichivirus A1. Biomed Sci Letters. 2019. 25: 331338.

Lee S, Bae KS, Lee JY, Joo YL, Kim JH, You KA. Development of molecular diagnostic system with high sensitivity for the 
detection of human sapovirus from water environments. Biomed Sci Letters. 2021. 27: 35-43.

National Institute of Environmental Research. Development and verification of genetically diagnostic method for the detection of non-regulated viruses from water environment (I). 2016. pp. 1-21. NIER, Incheon, Korea.

National Institute of Environmental Research. Development and verification of genetically diagnost2004ic method for the detection of non-regulated viruses from water environment (II). 2017. pp. 1-23. NIER, Incheon, Korea.

Parrón I, Plasencia E, Cornejo-Sánchez T, et al. Human astrovirus outbreak in a daycare center and propagation among household contacts. Viruses. 2021. 13: 1100.

Tamura K, Stecher G, Peterson D, Filipski A, Kumar S. MEGA6: Molecular evolutionary genetics analysis version 6.0. Mol Biol Evol. 2013. 30: 2725-2729.
Tan Y, He WT, Chen MM, Mo JJ, Ju Y, Chen M. An outbreak of human astrovirus lineage $1 \mathrm{~b}$ in a middle school in Guangxi, Southern China in 2017. Chin Med J. 2019. 132: 336.

Yi J, Lee JK, Chung EH, Cho DH, Kim EC. An outbreak of astrovirus infection of newborns with hemorrhagic diarrhea in a neonatal unit. Korean J Clin Microbiol. 2004. 7: 55-58.

https://doi.org/10.15616/BSL.2021.27.4.255

Cite this article as: Lee $\mathrm{S}$, Bae KS, Park J, Kim JH, Lee JY, Choi J, Park ER, You KA. Mornitoring and Identification of Human Astrovirus from Groundwater in Korea Based on Highly Sensitive RT-nested PCR Primer Sets. Biomedical Science Letters. 2021. 27: 255263. 